\title{
As escolas da Vila: Instituições escolares na Vila da Paz em Teresina (1980-1990)
}

\author{
The village schools: School institutions in Vila da Paz in Teresina (1980-1990) \\ Las escuelas del pueblo: Instituciones escolares de la Vila da Paz en Teresina (1980-1990)
}

Recebido: 21/04/2021 | Revisado: 29/04/2021 | Aceito: 04/05/2021 | Publicado: 16/05/2021

\author{
Karina Viana da Silva \\ ORCID: https://orcid.org/ 0000-0002-7289-6198 \\ Universidade Federal do Piauí. Brasil \\ E-mail: karina27viana@gmail.com \\ Marcelo de Sousa Neto \\ ORCID: https://orcid.org/0000-0002-2748-2316 \\ Universidade Estadual do Piauí, Brasil \\ E-mail: marcelo@ccm.uespi.br
}

\begin{abstract}
Resumo
O presente artigo tem como objetivo analisar o surgimento de instituições de ensino no contexto histórico da comunidade Vila da Paz, em Teresina-PI, por meio da análise da atuação socioeducacional de Pedro Balzi, padre que marcou seu sacerdócio em ações missionárias, dentre elas destacando-se a construção de escolas. A pesquisa buscou compreender como a implantação de estabelecimentos educacionais contribuiu para que ocorressem transformações no cenário da Vila. Identificou-se que às ações do clérigo, sobretudo no aspecto educacional, assumiram posição de destaque para a configuração histórica da Vila. Localizada na zona sul de Teresina, o objeto insere-se no recorte de 1980 a 1990, tomando como ponto de partida das análises o contexto social da capital na década de oitenta, marcada pelas ocupações irregulares no tecido urbano. A partir desses recortes, verificou-se que o trabalho desenvolvido por padre Balzi, principalmente por meio da construção de escolas, se revestiu no agente mobilizador das primeiras ações de urbanização na Vila da Paz, modificando o tecido urbano da cidade e do cotidiano de seus moradores. Nesse percurso, procurou-se estabelecer interlocuções com os escritos de Scott Mainwaring, Ana Fani Alessandri Carlos, Maurice Halbwachs, entre outros. Como lastro documental, a pesquisa apoiou-se em fontes bibliográficas, hemerográficas e relatos orais.
\end{abstract}

Palavras-chave: História; Educação; Memória; Igreja católica.

\begin{abstract}
This article aims to analyze the emergence of educational institutions in the historical context of the Vila da Paz, in Teresina-PI, community, through the analysis of the socio-educational performance of Pedro Balzi, a priest who marked his priesthood in missionary actions, among which the building schools. The research sought to understand how the implementation of educational establishments contributed to changes in the scenario of the Village. It was identified that the actions of the clergyman, especially in the educational aspect, assumed a prominent position for the historical configuration of the Vila. Located in the south of Teresina, the object is inserted in the 1980 to 1990 section, taking as a starting point of the analysis the social context of the capital in the eighties, marked by irregular occupations in the urban fabric. From these clippings, it was found that the work developed by Father Balzi, mainly through the construction of schools, became the mobilizing agent of the first urbanization actions in Vila da Paz, changing the urban fabric of the city and the daily lives of its residents. residents. Along this path, we sought to establish interlocutions with the writings of Scott Mainwaring, Ana Fani Alessandri Carlos, Maurice Halbwachs, among others. As a documentary backing, the research was based on bibliographic, hemerographic and oral reports.
\end{abstract}

Keywords: History; Education; Memory; Catholic church.

\section{Resumen}

Este trabajo tiene como objetivo analizar el surgimiento de las instituciones educativas en el contexto histórico de la comunidad Vila da Paz, Teresina-PI, a través del análisis de la actuación socio-educativa de Pedro Balzi, un sacerdote que marcó su sacerdocio en acciones misioneras, entre las que destaca la construcción de escuelas. La investigación pretendía comprender cómo la implantación de los centros educativos contribuyó a las transformaciones que se produjeron en la Vila. Se identificó que la acción del clérigo, especialmente en el aspecto educativo, asumió una posición importante para la configuración histórica de la Villa. Situado en la zona sur de Teresina, el objeto se inserta en el recorte de 1980 a 1990, tomando como punto de partida de los análisis el contexto social de la capital en la década de los ochenta, marcado por ocupaciones irregulares en el tejido urbano. A partir de estos recortes, se verificó que el trabajo desarrollado por el padre Balzi, principalmente a través de la construcción de escuelas, se convirtió en el agente movilizador de las primeras acciones de urbanización en Vila da Paz, modificando el tejido urbano de la ciudad y la vida cotidiana de sus habitantes. En este camino, se buscó establecer interlocuciones con los escritos de 
Scott Mainwaring, Ana Fani Alessandri Carlos, Maurice Halbwachs, entre otros. Como lastre documental, la investigación se basó en fuentes bibliográficas y hemerográficas y en informes orales.

Palabras clave: Historia; Educación; Memoria; Iglesia católica.

\title{
1. Introdução
}

\author{
"Se a educação sozinha não transforma a sociedade, \\ sem ela tampouco a sociedade muda" \\ Paulo Freire.
}

Produzir uma narrativa histórica que versa sobre a educação em um determinado contexto, nos leva a refletir sobre os ensinamentos do patrono da educação brasileira, muito porque é por meio da educação que se consegue notar as transformações e mudanças nos diversos cenários sociais. Nesse esteio, para ilustrar o que a reflexão de Freire informa no início do texto, é válido embarcar na história da comunidade Vila da Paz, localizada na zona sul da capital piauiense nas margens da BR 343 e em frente ao terminal rodoviário de Teresina, Vila que surgiu a partir de uma ocupação de terra ociosa em setembro de 1986 e marcada pela falta da infraestrutura básica.

Tão logo os sujeitos que ocuparam esse terreno, se encarregaram de iniciar a construção das casas, a maioria de barro e coberta de palha, com o passar do tempo e vivenciando as carências do lugar, as quais afetavam a todos, como a falta de abastecimento d'água, fornecimento de energia, pavimento das ruas, entre outras demandas, emergiu nos moradores o sentimento de união e manifestação junto ao poder público para dotar o novo lugar de moradia dos serviços essenciais ao viver citadino.

Além da força de mobilização dos primeiros moradores, é imprescindível mencionar a fundamental presença do padre Pedro Balzi, que escolheu a comunidade Vila da Paz como o último lugar para as suas ações missionárias. Dentre elas destacase a construção das escolas como uma das principais conquistas do trabalho social que o sacerdote desenvolveu naquele lugar, tanto pelo fato das crianças terem acesso à educação de qualidade nas proximidades de casa, como chamou a atenção dos entes públicos para a Vila.

Nesse sentido, metodologicamente, procurou-se analisar a atuação social do padre Pedro Balzi, buscando tecer uma narrativa que o destacasse no contexto histórico da Vila da Paz, no processo de organização dos espaços e do cotidiano do novo lugar de morada, posto que, na medida em que o seu trabalho se revestia na construção de obras, principalmente escolas, também forçava o poder público na implantação da infraestrutura necessária aos moradores.

Para escrita, utilizamos como referências, além da literatura existente sobre o tema e a legislação vigente no período, a documentação pertencente ao Arquivo Público do Estado do Piauí - APEPI, sobremaneira, a análise de jornais que circularam na cidade no período estudado, o que permitiu a construção de um diálogo que possibilitou novos olhares a respeito da história da Vila da Paz, bem como a reflexão sobre outras dimensões do tecido social local. Destacamos, ainda, o uso da Metodologia da História Oral para construção e a análise das fontes, em interlocução teórica com Maurice Halbwachs, Ana Fani Carlos e Scott Mainwaring. Ainda em relação às fontes orais, adotamos a História Oral Temática como meio para nos aproximar das memórias dos primeiros moradores que participaram desde o início da ocupação até a implantação dos serviços essenciais na comunidade, de modo que se concorda com Lucília Delgado quando ela pontua que as entrevistas temáticas "são entrevistas que se referem a experiências ou processos específicos vividos ou testemunhados pelos entrevistados” (Delgado, 2010, p. 22). 


\section{O Padre e a Vila: Espaços, Contextos e Ensino}

Abordar parte da configuração histórica da Vila da Paz é observar que durante o processo de definição dos seus espaços, a Igreja católica teve papel de destaque por meio de seus representantes e, de forma especial, por meio da presença do padre suíço Pedro Balzi, responsável por importante obra de evangelização, idealização e construção de igrejas e escolas na região.

Sobre a ocasião da chegada do padre Pedro na Vila da Paz, recorre-se ao fragmento do texto escrito por seu irmão e pelo próprio sacerdote, no qual o primeiro relata em linhas gerais o contexto adotado por Pedro e o próprio aborda minimamente a situação que escolheu para viver a sua mais nova missão, ao destacarem:

Em Teresina, capital do Estado do Piauí, na parte norte oriental do Brasil, Padre Pedro chega no dia 14 de março de 1987, justamente no terceiro aniversário da morte de sua mãe, coincidência na qual vê um motivo; é necessário esperar o mês de setembro para ter notícias suas na primeira carta brasileira, na qual não fala de si, mas limita-se a dizer: "Escrevo-lhes aqui da minha cabana, onde me sinto muito bem e com muita alegria no coração, porque posso viver no meio de pessoas mais necessitadas." Sobre a sua nova habitação não diz nada, mas sabemos que se trata de uma das muitas cabanas das favelas, feita de barro e palha, sem nenhum outro conforto além de um teto precário sobre a cabeça. (Balzi, 2013, p.13).

A partir da passagem, nos é evidenciado a satisfação de Pedro em poder servir os menos favorecidos, mesmo vivendo debaixo de uma cabana semelhante às demais em várias ocupações nas redondezas. A alegria sinalizada por ele também nos revela sobre a opção que fez ao dedicar o seu sacerdócio à ação missionária, pois é imprescindível, para a construção da narrativa sobre a atuação do padre no contexto de criação da Vila, entender sua posição na organização da instituição Igreja. Dentre as muitas comunidades missionárias ligadas à Igreja Católica, padre Pedro Balzi fazia parte da "Paradiso", de Bérgamo, na Itália, que pregava a construção de igrejas e estruturas paroquiais do alicerce até o total estabelecimento do prédio, cujo trabalho deveria ser destinado as localidades descristianizadas, os grandes bairros operários, de modo que nesses lugares a ação dos missionários possibilitasse a reconstrução de uma consciência religiosa e moral cristã, além de organizar a vida religiosa, que por vezes se daria em condições hostis.

Foi levando em consideração essas recomendações que padre Pedro deixou a Bolívia, depois de 22 anos onde já tinha desenvolvido um trabalho social representativo, sobretudo com a construção do hospital Juan XXIII, que era voltado especialmente para o atendimento das vítimas da hanseníase. Para dar continuidade a sua missão, Pedro aceitou o convite do então Arcebispo de Teresina, Dom Miguel Fenelon Câmara Filho (1984-2001), o qual tomou conhecimento sobre o trabalho do padre através das Irmãs Ursulinas, congregação que já o auxiliava na Bolívia. O bispo tomou, então, as providências para trazer o missionário para o Brasil, processo que se iniciou no final de outubro de 1986 e somente aprovado no dia 07 de março de 1987, refletindo a burocracia do Estado brasileiro, pois, segundo a compreensão do próprio Pedro: "Sempre havia novas dificuldades, novos documentos, novas assinaturas." (Balzi, 2009, p.13).

Ao chegar à Vila da Paz, segundo relatos orais dos moradores, bem como as próprias memorias de padre Pedro, ele não deixava de pôr em prática as funções do seu ofício, a celebração das missas se dava de forma improvisada na cabana que lhe foi cedida pelos moradores, com isso a primeira obra realizada na comunidade foi a construção da Igreja matriz de Nossa Senhora da Paz, com ajuda de doações dos benfeitores que Pedro mantinha contato por meio de cartas e e-mails.

A construção de qualquer estrutura em um dado espaço da cidade é sinal de transformação na paisagem urbana, que a todo momento está em constante processo de mudanças, que são pensadas e realizadas para atender ao desejo de se ter uma cidade idealizada a partir da concepção de quem promove as alterações. É nessa conformidade que se busca estabelecer um novo olhar para área renovada, além de uma nova dinâmica para o lugar, visto que segundo Ana Fani Alessandri Carlos: 
Os lugares transformados da cidade produzem nova dinâmica; as ruas redimensionam-se e ganham outro elemento, que tende a eliminar o lúdico, transformando-as em lugar de passagem. O processo de reprodução do espaço urbano vai-se constituindo por meio da eliminação de antigas formas que traziam a marca da sociabilidade - pontos de encontro, o lugar da festa -, tragando os rituais e seus mistérios, eliminando referências, destruindo com isso as bases de apoio da memória social. (Carlos, 2001, p. 34).

Foi uma nova dinâmica que padre Pedro Balzi, engendrou com suas obras sociais, na medida em que, para a construção dos estabelecimentos, o espaço da Vila da Paz foi redimensionado para receber a estrutura necessária à transformação da sua realidade, haja vista que a comunidade surgiu de uma ocupação sem nenhum planejamento urbanístico para atender as demandas dos sujeitos que não possuíam condições financeiras para assumir a prestação de uma casa, ou mesmo não se enquadrava nas exigências da política habitacional.

Nesse sentido, os sujeitos que ocuparam a Vila da Paz, foram tecendo o espaço conforme as suas necessidades, pois para a implantação dos serviços básicos muitas casas tiveram que ser removidas, por estarem desalinhadas. Essa foi uma das primeiras mudanças ocorridas no espaço da comunidade, as outras se constituíram a partir da ação do padre Pedro, tendo sido a Igreja a primeira obra a ser construída, como mencionado anteriormente.

Assim, reforçando o que Ana Fani destacou, a ação do padre Pedro, segundo relato de moradores, por vezes se dava na compra de casas ou espaços onde ocorriam festas, ou que eram habitadas por sujeitos tidos como violentos. Nesta perspectiva, de modo implícito, instaurando o novo em detrimento do antigo, ele removeu as referências e tentou substituir os elementos da memória social sobre a Vila da Paz, e com isso, fixar características positivas a fim de confeccionar uma nova memória a se desenvolver em cada indivíduo.

Para tanto, Maurice Halbwachs (1990) infere que a memória individual existe dentro de um grupo maior, o da memória coletiva, e que a individual encontra respaldo na coletiva, visto que os acontecimentos individuais adquirem sentido e significado porque derivam de ações coletivas, a julgar que a coletiva está a serviço da manutenção de um grupo. Soma-se a isso o fato que a memória individual não contrasta com a coletiva, porque precisa dela para continuar a existir. Nesse sentido, concorda-se com o autor sobre os quadros que essa apresenta de si mesma, haja vista que o sujeito procura apoio de suas memórias mais particulares nas memórias de outros.

Entre as várias memórias que se elevam sobre a atuação social do padre Pedro, evidenciou-se a educação, uma das primeiras preocupações expostas nas cartas que enviava aos amigos, na Itália e também na comunidade europeia, dentre os quais, a fundação Giusseppe Tovini, que foi alvo dos pedidos do sacerdote, foi instituída, segundo Angelo Zammarchi, por Vitororino Chizzolini em 1959. Um dos interesses da fundação em ajudar as obras sociais de padre Pedro, principalmente na construção das escolas, se justificava pelo fato que Giuseppe Antonio Tovini defendia a concepção de que as instituições católicas, especialmente as instituições educacionais, deviam buscar autonomia financeira plena. Conhecedor disso, Pedro encaminhava os pedidos de doações a essa instituição.

É importante esclarecer que grande parte do trabalho social desenvolvido por padre Pedro foi o resultado direto de doações que eram solicitadas, a princípio por meio de cartas, e, posteriormente, com o acesso à internet, os pedidos se davam pelo envio de e-mails. Nas cartas, ele descrevia a situação e solicitava ajuda para a construção dos estabelecimentos necessários para amenizar a condição de vida dos sujeitos que viviam na Vila da Paz, posto que, em uma das inúmeras cartas escritas, destacou que:

E depois, aqui falta de tudo e então é necessário fazer tudo! São necessários: um ambulatório para os doentes, um Centro para o bem de toda a população, especialmente das mulheres, para que possam aprender muitas coisas necessárias para a família: saúde (higiene, vacinação, pré-natal etc.), costura, alfabetização, culinária etc.[...] uma creche para as muitas crianças que têm a necessidade de tudo. (Balzi, 2013, p. 15). 
O trecho da carta traz questões pontuais, deixando clara a situação de vulnerabilidade vivida pelos moradores, e realçando a preocupação com as mulheres, porque as enxergava como membro fundamental na família, considerando ainda a construção de uma creche para o acolhimento das crianças, para que, com isso, os pais pudessem procurar um emprego. Nesse sentido, questionada sobre como se dava o acesso a recursos e se havia uma regularidade no repasse das doações, a presidente da fundação Nossa Senhora da Paz, a Sra. Antonia Rodrigues do Nascimento Barros, uma das primeiras moradoras participante da ocupação da Vila da Paz, além de ter presidido a associação de moradores da Vila da Paz por três mandatos, informa que:

Não, não havia regularidade era assim: se a gente pensasse em fazer uma obra né, aí a gente mandava pedir, ô vamos fazer obra tal e tudo. Não vinha todo mês, não vinha aquele dinheiro, e a gente....eu reclamava muito disso porque eu sou muito sistemática, eu gosto das minhas coisas todas organizadas e eu dizia padre Pedro como é que a gente vai gastar sem saber o quanto a gente tem né porque não tinha, aí assim vamos fazer agora a escola feminina aí mandavam, olha dezembro, no início que ele chegou aqui era escrevendo na mão, mandava umas 10 mil cartas para os amigos, olha mais ele sofria, isso aqui [gesto apontando para mão] eu acho que ele nem tinha, mais o dedo só de escrever, depois aí teve a datilografia na máquina depois o computador né, mas ele escrevia pra esses....aí assim digamos que ele mandava 2.000 mil cartas digamos que vinha $10 \%$ de resposta daquelas cartas, mas nem todas vinham assim 10, 20 mil não, vinha o que a pessoa podia mandar tá entendendo? Aí juntava tudo e a gente ia fazendo, só que tudo como eu disse pra você era..., foi e é muito bem aplicado nas coisas que a gente ia fazer né? Era uma pessoa que era organizada ao máximo no sentindo de..., era pra comprar essa cadeira era pra comprar essa cadeira cadê a nota? Cadê tudo? (BARROS, 2018).

O procedimento descrito na fala da entrevistada exemplifica como se dava o pedido das doações, e como era feito o gerenciamento dos recursos. Evidencia também o constante exercício que padre Pedro fazia para conseguir os recursos para a construção dos estabelecimentos, conforme surgia a necessidade dos moradores da comunidade. Mais uma vez, a história oral se eleva pela insuficiência da produção escrita sobre o cotidiano dos moradores nos primeiros anos da ocupação, a oralidade tornou-se imprescindível para a construção da configuração histórica da Vila da Paz e assim poder colocar em prática o desafio proposto por Philippe Joutard ao mencionar que é preciso "ouvir a voz dos excluídos e dos esquecidos; trazer à luz as realidades "indescritíveis", quer dizer, aquelas que a escrita não consegue transmitir; testemunhar as situações de extremo abandono" (Joutard, 2000, p.33).

Ainda sobre a fala da entrevistada ela destaca, a construção da escola de ensino fundamental voltada para o atendimento das jovens e mais uma vez ressalta a questão da aplicabilidade, bem como destaca a organização do clérigo na exigência das notas fiscais de todos os materiais comprados, confirmada em pesquisa realizada no Memorial, onde foram verificados muitos recibos de lojas de materiais de construções, os quais informavam transações que variavam entre dois mil a cinco mil reais, para a construção de quadras e o retelhamento da Unidade Básica de Saúde.

Sobre o recebimento de doações, é válido mencionar que essas não são alvos de tributação, dado o contexto religioso, visto que as Igrejas de qualquer culto não sofrem tributação, como disposto pelo artigo 150, inciso VI da Constituição Federal, na qual a lei veda que a União, aos Estados, o Distrito Federal e os Municípios estabeleçam impostos a estas instituições, bem como abrange as rendas e serviços relacionados à sua manutenção e as organizações que administram o funcionamento e garante recursos para outras entidades.

Nesse sentido, dentre os impostos que não incidem sobre as igrejas estão: o Imposto Predial e Territorial Urbano (IPTU), Imposto de Renda (IR), Contribuição para o Financiamento da Seguridade Social (COFINS), Imposto Sobre Circulação de Mercadorias e Serviços (ICMS) e Imposto sobre Transmissão Causa Mortis e Doação (ITCMD). Dessa maneira, as doações recebidas por padre Pedro Balzi se enquadravam neste último imposto, sobre isso recorre-se à fala da presidente da fundação ao ser questionada sobre o posicionamento do poder público frente ao repasse das doações. 
[...] As Igrejas não pagam certos impostos então são livres, como dinheiro que era repassado vinha em forma de doação não tinha o menor problema era só justificar as doações, por exemplo, veio pra fazer a creche está aqui a creche todas as notas fiscais tudo, tudo, tudo a planta baixa, planta alta, era só isso né não tinha dificuldade não quando vinha em dólar ou euro, aí a gente trocava normalmente pela moeda daqui e pronto a gente nunca teve muito problema não, nunca teve problema até porque vinha em forma de doação e todas as doações eram aplicadas para um determinado fim então a gente nunca teve problema. (Barros, 2018).

As doações recebidas para a construção das obras sociais, segundo o relato, eram justificadas com a apresentação das notas fiscais e das plantas das construções, visto que a fundação apresenta a sua prestação de contas junto ao Ministério Público do Piaú, por meio da procuradoria-geral de justiça, na qual o promotor da vigésima quinta promotoria de justiça de Teresina emiti atestado sobre o exercício financeiro da instituição social. Assim, não cabia ao Estado estabelecer qualquer empecilho, pois o padre Pedro assumiu o papel que concernia ao poder público em ajudar a dotar a cidade da infraestrutura necessária para que os cidadãos possam gozar dos seus direitos.

Para melhor administrar os recursos na forma de doações, padre Pedro criou, em 1992, a Fundação Nossa Senhora da Paz, da qual foi o primeiro presidente, seguido até os dias atuais por Antonia Rodrigues do Nascimento Barros, cujo principal objetivo é "formar bons cristãos". O campo de atuação da fundação está relacionado diretamente com a formação humana integral, sendo esta a responsável pelo gerenciamento da educação a nível infantil até o médio, as escolas inicial e fundamental estão localizadas na Vila da Paz, e o ensino médio na vizinha comunidade de São José da Costa Rica, e também no Parque Rodoviário há a Creche Maria Auxiliadora, que, de maneira semelhante, foi construída por meio de doações. Sobre esta, a presidente da fundação relatou que:

Um amigo do padre Pedro mandou um dinheiro e nós construímos a creche Maria Auxiliadora no Parque Rodoviário e a casa dos idosos, que não é mais aquela dali era outra bem bonita que a gente fez, teve que desmanchar pra fazer o prédio do abrigo né, mas tudo muito bem aplicado tá, não caiu nada do céu assim joga dinheiro lá ou então vem de dinheiro de bolo, não, os amigos de padre Pedro foi quem ajudaram a construir tudo isso aqui etapa por etapa e comprar essas casas que nós compramos tudo aqui foi comprado. (Barros, 2018).

O relato chama atenção para a direção que os recursos eram encaminhados, ressaltando ainda sua aplicabilidade de acordo com as necessidades que surgiam no contexto da Vila, e nas comunidades próximas, sendo as obras realizadas conforme o volume de dinheiro que chegava, o que, segundo ela, não era em grande quantidade, mas foi a base de todas as etapas das construções.

Ainda sobre a fundação, pode-se constatar que essa também se originou como uma maneira de acabar com as desavenças entre as duas associações de moradores que existiam na Vila, fato destacado pela impressa local,

Desde que surgiu, em 1987, a Vila da Paz vem sendo marcada por desentendimentos entre as duas associações de moradores do local. A Vila, que fica em frente ao terminal rodoviário, na zona sul, foi formada a partir de uma grande invasão e abriga hoje cerca de 2.500 famílias. As duas associações que disputam a preferência dos moradores são a Associação Comunitária de Moradores, presidida por Fátima Alves de Oliveira, e a Associação dos Moradores da Vila da Paz, dirigida por Antônia Rodrigues do Nascimento. "Nós temos realmente linhas de trabalho diferente e procuramos sempre manter a nossa independência, principalmente de partidos políticos" explica Antônia Rodrigues do Nascimento, conhecida no bairro como Toinha. (O Dia, s/a).

O texto jornalístico expõe muitas informações, o primeiro ponto diz respeito a data em que surgiu a Vila da Paz, colocado como 1987, quando de fato foi em setembro de 1986; o segundo, refere-se ao discurso construído pelo suposto proprietário do terreno, para quem o movimento de entrada no espaço que se tornaria a Vila se tratava de uma invasão, embora a área estivesse abandonada, além de não se encontrar registrada na Prefeitura; e, terceiro, o papel da mídia na condição de legitimadora da versão oficial. Ainda por meio do fragmento, nota-se a força de representatividade que os moradores adquiriram, empreendendo manifestações para o alcance dos serviços básicos, de modo que sugiram duas associações. 
Além disso, a procura por meios para estabelecer a fronteira entre as ações sociais realizados pelo padre Pedro, representante da Igreja, e a política, pois o posicionamento adotado pela instituição foi motivo da tensa relação estabelecida entre o Estado brasileiro e a Igreja Católica, no contexto da ditadura civil militar. No entanto, no caso da comunidade, essa ligação foi renovada, à medida em que a presidente da Associação dos Moradores da Vila da Paz, que, a princípio, tentou manter o distanciamento com a questão política, estreitou essa relação na condição de presidente da fundação, quando buscou o convênio com os entes políticos para as escolas, haja vista que a atuação social do padre Pedro construía as instalações, e o poder público assumia a responsabilidade pelo pagamento dos professores e funcionários e a alimentação dos alunos.

Ainda sobre a relação mantida com os entes políticos, a presidente da fundação destacou que, "quando começamos as obras aqui da fundação já foi o Heráclito Fortes que ajudou muito nos calçamentos, nas duas passarelas foi o Heráclito Fortes que fez" (Barros, 2018). O trecho reforça a ideia de que as obras sociais, desenvolvidas por Pedro, forçaram o poder público na implantação das melhorias no espaço da Vila da Paz, bem como evidencia que a memória é um ato político, na concepção de que o sujeito é influenciado por suas vivências, o seu contexto e condição social.

Dessa maneira, a fundação desenvolveu e desenvolve um papel muito importante no contexto da Vila da Paz, empregando as pessoas da comunidade, nas escolas, local da principal frente de atuação da instituição, visto que:

[...] Hoje nós temos não sei se é a maioria muita gente realmente empregada aqui na fundação a gente priorizou as pessoas da comunidade foi uma briga quando a gente abriu as escolas porque não poderia se botar pessoas sem concurso e nós conseguimos inserir foi uma briga muito grande até contra os vereadores da época que não aceitavam e a briga foi grande e a gente conseguiu inserir essas pessoas na fundação, ela conseguiu empregar muita gente. (Barros, 2018).

Na passagem, Antonia destaca a dificuldade para conseguir empregar os moradores, ao considerar que a legislação exige que a contratação seja realizada por meio de concurso público. No caso da fundação, foi estabelecido o vínculo empregatício por meio da contratação do serviço prestado, que, implicitamente, se constituía uma forma de controle social, mas se tornou um meio para a mudança de vida de parte da população da Vila da Paz, dada as condições de desemprego que afligia aqueles sujeitos.

Atualmente, a fundação desenvolve muitos projetos voltados para educação e a prática de esportes, contudo, segundo a presidente, depois do falecimento do padre Pedro, ocorrido em 05 de outubro de 2009, as doações diminuíram, e a saída encontrada foi a produção de projetos que são apresentados ao poder público, e apreciados, caso, aprovados, a verba é repassada, para o desenvolvimento dos projetos junto à comunidade escolar.

A educação, que tanto foi prezada nas ações do padre Pedro Balzi, foi responsável por uma das transformações do espaço da Vila da Paz, como a Creche Nossa Senhora da Paz, construída, em 1991, para receber e ensinar as primeiras lições as muitas crianças que passavam o dia a vagar nas ruas, expostas ao perigo de atravessar a movimentada BR-343 para ir à rodoviária, muitos na condição de pedintes, ou fazendo pequenos serviços de carregador de malas, ou mesmo realizando pequenos furtos. Como destacado por jornal da época, "é grande a quantidade de crianças que estão sem escola e vivem nas proximidades da Rodoviária praticando pequenos furtos ou carregando volumes para passageiros" (Jornal da Manhã, 1987, p.3). Essa situação preocupava Pedro, que logo buscou ajuda fora do país para a construção da creche.

Diante do grande número de alunos que saía da creche e que não conseguia vaga na única escola primaria construída na comunidade, a unidade de ensino Professor Alcides Lebre, inaugurada em 1988, com uma pequena extensão, formada por apenas seis salas de aula, se mostrou incapaz de atender o público-alvo. Em notícia vinculada nos periódicos da época, retratava-se a dificuldade do acesso à educação, uma vez que, "A educação também é deficiente, pois existe apenas uma escola que atende só no curso primário obrigando muita gente a se locomover para outros bairros como o Morada Nova" (O Dia, 1991, p.02). 
Em virtude disso, depois da construção da creche, Pedro viu novamente a necessidade de edificar uma escola de Ensino Primário com capacidade para receber 700 alunos divididos em dois turnos. Entretanto, mais uma vez, surge a necessidade de acolhimento dos alunos que saiam da escola primária para o fundamental, o que levou padre Pedro a construir as escolas técnicas Nossa Senhora da Paz, que ofereciam cursos profissionalizantes preparando o jovem para o mercado de trabalho.

Para o atendimento dos alunos a nível fundamental, padre Pedro resolveu fazer a separação entre os alunos e alunas, de modo que construiu prédios separados para abrigar os alunos, evitando o contato entre os adolescentes, reforçando a sua postura conservadora, imprimindo a marca no ensino disciplinador e voltado para o aspecto religioso.

Sem dúvidas a educação foi o marco na atuação social do padre Pedro Balzi, considerando que, depois do ensino fundamental, surgiu a necessidade da escola de nível médio, pois para ter acesso ao ensino os alunos se deslocavam até o bairro Lourival Parente, para onde muitos iam a pé por falta da condição financeira para pagar a passagem de ônibus. Nesse cenário, padre Pedro novamente, com auxílio das doações, construiu as dependências que abrigaria a unidade de ensino, buscando convênio com o poder público para o funcionamento da escola, que a princípio decidiu adotar professores estagiários do Estado, que foram remunerados com bolsas.

\section{Considerações Finais}

Ao fim da pesquisa, nos foi possível observar que muitas foram as faces assumidas por padre Pedro Balzi, dentre as quais se procurou colocar em evidência a educação ao longo do artigo, além de benfeitor social que edificou obras para transformar o cotidiano de necessidades vividos pelos moradores daquela comunidade. No universo religioso, destaca-se como "homem de oração" dedicado ao sacerdócio, com uma personalidade conservadora muito condizente com sua formação, assegurada com a ordenação sacerdotal em 3 de junho de 1950 na catedral de Bérgamo na Itália, tendo sido essa característica estendida no gerenciamento do ensino, marca indelével do seu trabalho social desenvolvido no espaço da Vila da Paz.

A educação foi o principal alvo de suas ações, pois padre Pedro compreendeu que, diante da realidade que ele próprio vivenciou de perto, apenas a educação seria capaz de transformar a comunidade, que ele acompanhou e colaborou diretamente para o desenvolvimento do lugar que nasceu sob o signo da carência. O ensino, sem dúvidas, foi privilegiado por sua vontade de construir instalações que se iniciava do alicerce até a mobília das escolas, que atendem desde o nível infantil até o ensino médio, bem como favoreceu a educação com tendência profissional. Padre Pedro Balzi, por meio de sua atuação sacerdotal, conseguiu transformar profundamente o cotidiano da Vila da Paz, em Teresina, sobremaneira, seu cotidiano escolar, e dessa forma marcando a memória da Vila e da cidade.

\section{Referências}

Andreola, B. A. (2011). Por uma pedagogia das grandes urgências planetárias. Revista do Centro de Educação, 36 (2), 313 -330.

Balzi, G, \& Cariissoni, A. (Ogr.). (2013). Construtor de Amor: Padre Pedro Balzi. Halley.

Balzi, P. (2009). História da Paróquia Santuário Nossa Senhora da Paz: Gráfica do Povo.

Barcelar, O. I. B. (1980). Fluxos migratórios e crescimento urbano piauiense. Carta CEPRO. 6 (1) 25-36.

Barcelar, O. I. B. (1990). Causas e tendências do processo migratório piauiense. Fundação CEPRO.

Barros, A. R. N. (2018). Entrevista concedida a Karina Viana da Silva, nas instalações da Fundação Nossa Senhora da Paz. 09 out.

Brigas. (1987). O Dia. Recorte de jornal presente no acervo do Memorial padre Pedro Balzi.

Camargo, A. (1999). Como a História Oral chegou ao Brasil: entrevista com Aspásia Camargo por Maria Celina d'Araújo. História Oral. Revista da Associação Brasileira de História Oral. 2, 167-179. 
Research, Society and Development, v. 10, n. 5, e56610515292, 2021

(CC BY 4.0) | ISSN 2525-3409 | DOI: http://dx.doi.org/10.33448/rsd-v10i5.15292

Carlos, A. F. A. (2007) O Espaço Urbano: novos escritos sobre a cidade. FFLCH.

Corrêa, R. L. (2004) O espaço Urbano. Ática.

Delgado, L. A. N. (199). História Oral: memória, tempo, identidade. (2a ed.), EDUSC.

Façanha, A. C. (2003). A evolução urbana de Teresina: passado, presente e... Carta CEPRO, 22(1), 59-69.

Fontineles, C. C. S. (2015). O Recinto do Elogio e da Crítica: maneiras de durar de Alberto Silva na memória e na história do Piauí. EDUFPI.

Fontineles, C. C. S., \& Sousa Neto, M. (2017). Nasce Um Bairro Renasce A Esperança: história e memória de moradores do Conjunto Dirceu Arcoverde. Teresina: EDUFPI

Halbwachs, M. (1990). A memória coletiva. Ed. Revista dos Tribunais Ltda.

Mainwaring, S. (2004). A Igreja Católica e a política no Brasil (1916-1985): trad. Heloisa Braz de Oliveira Prieto. Brasiliense. 2004.

Moradores da Vila (1987). Jornal da Manhã, 05 jul. p. 3.

Moradores da Vila (1991). O Dia, 02/03 jun. 02.

Sousa Neto, M., \& Silva, K.V. (2019) A Cidade em Guerra: a Vila da Paz e sua história (Teresina, 1986-1990). Cadernos do Tempo Presente / UFS. 9, 63 80. https://doi.org/10.33662/ctp.v9i2.11170

Sousa Neto, M., \& Fontineles, C. C. S. (2019). Para além das margens: o Conjunto Habitacional Itararé e as remodelações dos espaços urbanos em Teresina (década de 1970). História Oral. 22, 191-216. https://doi.org/10.51880/ho.v22i2.942 